\title{
Clinical predictors of cognitive impairment and psychiatric complications in Parkinson's disease
}

\author{
Preditores clínicos de transtorno cognitivo e complicações psiquiátricas na doença de \\ Parkinson
}

Lidiane S. Campos, Rachel P. Guimarães, Luiza G. Piovesana, Paula C. de Azevedo, Leonilda M. B. Santos, Anelyssa D’Abreu

\begin{abstract}
Objective: To estimate the clinical and demographics aspects that may contribute to cognitive impairment and psychiatric symptoms in Parkinson's disease (PD). Method: All patients answered a structured standardized clinical questionnaire. Two movement disorders specialists performed the following scale: Unified Parkinson's disease rating score (UPDRS), the modified Hoehn and Yahr staging, Schwab and England Scale, SCOPA cognition (SCOPA-COG), SCOPA-Psychiatric complications (SCOPA-PC) and Non-Motor Symptoms Scale (NMSS). We built a generalized linear model to assess predictors for the SCOPA-COG and SCOPA-PC scores. Results: Almost 37\% of our patients were demented as per SCOPA-COG scores. Level of education and the UPDRS-Subscale III were predictors of cognitive impairment. Higher scores in domain 3 of NMSS and male gender were associated with psychiatric complications as assessed per the SCOPA-PC. Conclusion: Level of education and disease severity are predictors of dementia in PD. Psychiatric complications are more commonly observed in men.
\end{abstract}

Keywords: Parkinson, cognition, psychiatric status rating scales, dementia, risk factors.

\section{RESUMO}

Objetivo: Estimar aspectos clínicos e demográficos que podem contribuir para o comprometimento cognitivo e sintomas psiquiátricos na doença de Parkinson (DP). Método: Todos pacientes responderam questionário clínico padrão. Duas especialistas em distúrbios do movimento aplicaram as seguintes escalas: Unified Parkinson's disease rating score (UPDRS), Hoehn and Yahr estágios, Schwab and England Scale, SCOPA cognição (SCOPA-COG), SCOPA-Complicações psiquiátricas (SCOPA-CP) e Escala de sintomas não motores (NMSS). Utilizamos análise multivariada, para avaliar os preditores relacionados ao SCOPA-COG e SCOPA CP. Resultados: Aproximadamente 37\% dos nossos pacientes foram classificados como dementes utilizando-se os valores obtidos no SCOPA-COG. Nível educacional e a parte III do UPDRS foram preditores de comprometimento cognitivo. Escores elevados no domínio 3 do NMSS e sexo masculino associaram-se com complicações psiquiátricas quando acessadas pelo SCOPA-CP. Conclusão: Nivel educacional e gravidade de doença são preditores de demência na DP. Complicações psiquiátricas são mais comumente observadas em homens.

Palavras-chave: Parkinson, cognição, escalas de graduação psiquiátrica, demência, fatores de risco.

Parkinson disease (PD) is characterized by a combination of motor and non-motor symptoms (NMS). While the motor symptoms are well defined, the NMS could be underestimated. The prevalence of NMS after 7 years of disease duration is around $90 \%^{1}$ and several studies showed that NMS, such as psychiatric disorders and cognitive impairment could be potentially exacerbated by the treatment.

The prevalence rate of PD has been estimated in $3.3 \%$ in the Brazilian population². Cognitive impairment is a common NMS in PD patients, and increasing age, older age at onset of disease, longer disease duration, severity of parkinsonism, male gender, higher doses of antiparkinsonian drugs and the presence of psychiatric symptoms have been linked to increased risk of developing dementia ${ }^{2,3}$. Despite the high impact in quality of life of PD patients ${ }^{4}$ the incidence and prevalence rates of cognitive impairment and psychiatric symptoms in Brazilian PD patients are scarce ${ }^{5}$.

Therefore we evaluated the demographic and clinical characteristics of a cohort of Brazilian PD patients, using validated scales to assess the motor symptoms and NMS. Our goal was

Universidade Estadual de Campinas, Campinas SP, Brazil.

Correspondence: Lidiane S Campos; Universidade Estadual de Campinas; Cidade Universitária Zeferino Vaz; $13083-888$ Campinas SP, Brasil; E-mail: lidianecampos@yahoo.com.br

Conflict of interest: There is no conflict of interest to declare.

Support: CNPq (grant number 474873/2010-2).

Received 30 September 2014; Received in final form 10 December 2014; Accepted 30 December 2014. 
to estimate the frequency of cognitive impairment, and to evaluate clinical and demographic aspects that may contribute to cognitive impairment and psychiatric complications in PD.

\section{METHOD}

\section{Subjects}

We performed a cross-sectional study. We consecutively recruited 76 subjects who fulfilled the Brain Bank Criteria ${ }^{6}$ for PD diagnosis from the Movement Disorders Outpatient Clinic at Universidade Estadual de Campinas, University Hospital. All patients signed an informed consent approved by the local ethics committee prior to any research related procedure. Exclusion criteria was inability to read or understand Portuguese (e.g., illiteracy, severe dementia); history of severe brain injury, serious medical illness, psychiatric disorders other than depression prior to PD diagnosis, substance abuse, sensory deficits, delirium and refusal to participate in the study. Subjects on psychiatric medication such as antidepressants and antipsychotics were not excluded.

All patients answered a structured standardized questionnaire that covered age, gender, years of education, clinical information on PD (age at onset, duration of disease, side of onset and drug treatment), family history and past medical history.

Two movement disorders specialists (LSC and AD) examined all patients using the following validated scales:

(1) Unified Parkinson's disease rating score (UPDRS) ${ }^{7}$ : The UPDRS consists of 42 items which are grouped in four sections: subscale I - mentation, behavior, and mood section; subscale II - activities of daily living; subscale III - motor examination; subscale IV - complications of therapy. Higher scores reflect higher severity;

(2) The modified Hoehn and Yahr staging $(H \& Y)^{8}$;

(3) Schwab and England Scale (SES) ${ }^{9}$;

(4) SCOPA cognition (SCOPA-COG $)^{10}$ : comprises 10 items assessing 4 neuropsychological domains: attention, memory, executive functions, visuospatial abilities. Total score ranges from 0 to 43. Higher scores indicate better performance. We determine the diagnosis of dementia in subjects with scores 17 or lower ${ }^{11}$;

(5) SCOPA-Psychiatric complications (SCOPA-PC) ${ }^{12}$ : The SCOPA-PC consists of seven items: "hallucinations," "illusions," "paranoid ideation," "altered dream phenomena, "confusion," "sexual preoccupation," and "compulsive behavior". Each item is rated on a scale from 0 (no symptoms) to 3 (severe symptoms). The SCOPA-PC maximal score is 24;

(6) Non motor symptoms scale (NMSS) ${ }^{13}$ : The NMSS is a 30-item measure whose items are grouped into nine relevant domains: cardiovascular; sleep/fatigue; mood/apathy; perceptual problems/hallucinations; attention/memory; gastrointestinal tract; urinary function; sexual function; and miscellaneous. Score for each item is based on a multiple of severity (from 0 to 3 ) and frequency scores (from 1 to 4 ). The scale can therefore capture symptoms that are severe but relatively infrequent and those that may be less severe but persistent. The time frame is the previous month. The theoretical maximal total score is 360 points.

We classified subjects into two clinical subtypes: tremordominant (TD) and rigid-akinetic (RA) - no resting tremor. For this we used the items 20 (tremor) and 22 (rigidity) from the UPDRS. For the RA subtype, subjects had a score $\leq 1$ on item 20 and a score $\geq 1$ on item 22 . The TD subgroup had a score $>1$ on item 20 . We avoided further classification into more subtypes due to the small sample size. Neuropsychological and motor tests were conducted in the "on" stage for all patients who used levodopa or dopamine agonists and experienced motor fluctuations.

\section{Statistical analysis}

Demographic data were summarized as mean \pm standard deviation and frequencies (percentages). For each scale we presented values at percentile 50 and maximal possible scores (Table 1).

Missing data was considered to be missing at random. Side of onset was missing in 2 subjects and we imputed side of onset as the right side. Years of education were missing in two subjects and we imputed the mean years of education of the remaining sample in those two (7.54 years). At first, we analyzed the correlation between variables using bivariate Pearson correlation analyses. We performed a generalized linear model (GLM) using the SCOPA-COG as the dependent variable and age, sex, years of education, side of onset, clinical subtype, duration of levodopa treatment and disease duration as the independent variables. The clinical scales with a significant correlation with the SCOPA-COG scores were also included as covariates in this model. As a confirmatory analysis, we used logistic regression using the goodness of fit and C-statistics to model the presence of dementia controlling for age and gender. Only the covariates, which were significant in the GLM, were included in this secondary analysis, due to the small number of cases.

We also built a GLM to assess predictors for the SCOPA-PC scores using age, sex, and years of education, duration of levodopa treatment, side of onset, clinical subtype and disease duration. The clinical scales with a significant correlation with the SCOPA-PC scores were included as covariates in this model. We completed an ad-hoc analysis excluding the four subjects with missing data to confirm the results. We performed the analysis using STATA version 13.1, and significance level was established at $\alpha=0.05$.

\section{RESULTS}

We fully evaluated 76 subjects, 55 (72.37\%) male, age $58.81 \pm 10.00$ years $(33-82)$, mean years of education $7.54 \pm 4.46$ (1-20), and duration of disease of $8.73 \pm 7.21$ years (0.66-37 years). Nineteen patients $(25 \%)$ were rigid-akinetic 
and $57(75 \%)$ were tremor dominant. There was no significant difference in mean SCOPA-COG scores $(\mathrm{t}=2.0493$, $\mathrm{p}=0.0505)$ and frequency of dementia between both clinical subtypes (Pearson Chi-Square $(1)=1.2063, \mathrm{p}=0.272$ ). Thirty-nine subjects had symptom onset at left (53.42\%). Seventy-four subjects were receiving dopaminergic treatment. Further treatment is detailed in Table 2 and the results of the clinical assessment are summarized in Table 1.

Using the SCOPA-COG cutoff of 17, we classified $48(63.16 \%)$ PD patients as non-demented and $28(36.84 \%)$ as demented ${ }^{11,14}$. The cognitive impairment profile was worst in the memory assessment (Table 2). SCOPA-COG total scores displayed a statistically significant correlation with age $(\mathrm{r}=-0.25$; $\mathrm{p}=0.03)$, years of education $(\mathrm{r}=0.48$; $\mathrm{p}<0.0001)$, disease duration $(r=-0.23 ; p=0.045)$; UPDRS $(r=-0.48, p<0.001)$; UPDRS-Subscale I ( $r=-0.44, p=0.0001)$; UPDRS-Subscale III $(\mathrm{r}=-0.58 ; \mathrm{p}<0.001)$; HY $(\mathrm{r}=-0.42 ; \mathrm{p}=0.0002)$; SES $(\mathrm{r}=0.49$; $\mathrm{p}<0.0001)$, NMSS $(\mathrm{r}=-0.36, \mathrm{p}=0.0012)$.

We used a GLM to assess the predictors of final SCOPA-COG total score. In our first model, we controlled for age, gender, side of onset, clinical subtype, disease duration, years of study and the scores for the UPDRS, HY, NMSS, SCCP and SES. For this model, total years of study were the only significant predictor of final SCOPA score. Holding all other covariates constant, an additional year of education increased the final SCOPA score by $0.57 \pm 0.15(\mathrm{z}=3.90, \mathrm{p}<0.001$ : $95 \% \mathrm{CI}=0.28-0.86)$. Since there was a moderate correlation between the SCOPA-COG score and the UPDRS-Subscale III, we built a second model substituting UPDRS-Subscale I and UPDRS-Subscale III scores for the total UPDRS score. For each additional point at the UPDRS-Subscale III, holding all other covariates constant, the SCOPA-COG score would decrease by $0.34 \pm 0.15(z=-2.30, p=0.021,95 \% C I=-0.63,-0.05)$. We also observed in this model that controlling for all other variables; an additional year of education would increase the final SCOPA-COG score by $0.53 \pm 0.14$ ( $\mathrm{z}=3.74, \mathrm{p}<0.001$ : $95 \% \mathrm{CI}=0.25,0.81)$. Lastly, we performed a logistic regression based on the diagnosis of dementia as per SCOPA-COG scores, controlling for age and gender, using years of study and UPDRS-Subscale III scores as covariates. For each additional year of schooling the odds of dementia was 27 per cent lower $(\mathrm{OR}=0.73 \pm 0.08 ; \mathrm{z}=-2.9 ; \mathrm{p}=0.005 ; 95 \% \mathrm{CI}=0.59,0.91)$, while for each one point increase in the UPDRS-Subscale III score the odds of dementia was 22 percent higher $(\mathrm{OR}=1.21 \pm 0.07$; $\mathrm{z}=3.62 ; \mathrm{p}<0.01 ; 95 \% \mathrm{CI}=1.09,1.35)$. This model had good calibration (Hosmer-Lemeshow Chi-Square $(8)=2.11$; p = 0.9776) and very good discrimination (area under the receiver operator curve-AUROC $=0.88$ ). The mean SCOPA-COG scores were not significantly different in subjects using biperiden $(\mathrm{t}=0.46$, $\mathrm{p}=0.64)$ and on dopaminergic therapy $(\mathrm{F}=1.11, \mathrm{p}=0.35)$.

Only eleven subjects (14.5\%) had a SCOPA-PC of zero, which means no psychiatric symptoms. SCOPA-PC total scores displayed a statistically significant correlation with SCOPA-COG ( $r=-0.34 ; p=0.002)$; UPDRS $(r=0.53$; $p<0.001)$; UPDRS-Subscale I ( $r=0.56 ; p<0.001)$; UPDRS-Subscale III $(\mathrm{r}=0.47 ; \mathrm{p}<0.001) ; \mathrm{H} \& \mathrm{Y}(\mathrm{r}=0.37 ; \mathrm{p}=0.001)$; SES $(\mathrm{r}=-0.41$; $\mathrm{p}=0.002)$; NMSS $(\mathrm{r}=0.65, \mathrm{p}<0.001)$. The mean SCOPA-PC scores were not significantly different in subjects using amantadine $(\mathrm{t}=-1.45 ; \mathrm{p}=0.15)$, biperiden $(\mathrm{t}=0.36, \mathrm{p}=0.71)$ and dopaminergic therapy $(\mathrm{F}=0.43, \mathrm{p}=0.73)$.

Table 1. Clinical evaluation.

\begin{tabular}{|c|c|c|c|c|}
\hline Clinical scale & Mean \pm SD & Range & Values at percentile 50 & Possible maximal scores \\
\hline UPDRS & $34.90 \pm 20.00$ & $2-95$ & 32 & 156 \\
\hline Part I of UPDRS & $2.28 \pm 2.08$ & $0-10$ & 2 & 16 \\
\hline Part III of UPDRS & $16.48 \pm 8.42$ & $4-44$ & 15 & 56 \\
\hline Schwab and England (\%) & $72.89 \pm 22.26$ & $10-100$ & 80 & 100 \\
\hline Hoehn and Yahr & $2.53 \pm 1.05$ & $1-5$ & 2.5 & 5 \\
\hline SCOPA-PC & $2.60 \pm 2.40$ & $0-11$ & 2 & 24 \\
\hline NMSS total & $68.81 \pm 46.42$ & $1-196$ & 57.5 & 360 \\
\hline Dom1 & $2.54 \pm 3.87$ & $0-15$ & 0 & 24 \\
\hline Dom2 & $10.93 \pm 9.22$ & $0-32$ & 8 & 48 \\
\hline Dom3 & $13.99 \pm 16.7$ & $0-64$ & 6.5 & 72 \\
\hline Dom4 & $2.45 \pm 4.96$ & $0-22$ & 0 & 36 \\
\hline Dom5 & $8.21 \pm 9.02$ & $0-36$ & 5 & 36 \\
\hline Dom6 & $5.26 \pm 6.91$ & $0-26$ & 2.5 & 36 \\
\hline Dom7 & $10.54 \pm 10.22$ & $0-36$ & 7 & 36 \\
\hline Dom8 & $5.88 \pm 7.91$ & $0-32$ & 2 & 24 \\
\hline Dom9 & $8.68 \pm 7.49$ & 0.25 & 7.5 & 48 \\
\hline SCOPA-COG & $19.38 \pm 6.65$ & $2-34$ & 20.5 & 43 \\
\hline Memory & $6.76 \pm 2.88$ & $0-15$ & 7 & 22 \\
\hline Visuospatial function & $3.34 \pm 1.20$ & $0-5$ & 4 & 5 \\
\hline Attention & $2.30 \pm 1.33$ & $0-4$ & 2 & 4 \\
\hline Executive function & $6.90 \pm 2.61$ & $2-12$ & 7 & 12 \\
\hline
\end{tabular}

SD: Standand deviation; UPDRS: Unified Parkinson's disease rating score; NMSS: Non-motor symptoms scale; SCOPA-COG: SCOPA cognition. 
Table 2. Use of antiparkinsonian medication.

\begin{tabular}{lc}
\hline Medication & N (\%) \\
\hline Dopaminergic medication & $74(98 \%)$ \\
Levodopa & $41(53.95 \%)$ \\
Pramipexol & $11(14.47 \%)$ \\
Levodopa + Pramipexol & $22(28.95 \%)$ \\
Selegiline & $2(2 \%)$ \\
Anticholinergic (Biperiden) & $15(19 \%)$ \\
Amantadine & $16(21 \%)$ \\
Quetiapine & $6(8 \%)$ \\
Antidepressants & $56(73 \%)$ \\
\hline
\end{tabular}

Holding all covariates constant, women had a 1 point lower SCOPA-PC score when compared to men $(\mathrm{z}=-2.02$; $\mathrm{p}=0.043 ; 95 \% \mathrm{CI}=-1.98,-0.02$ ), while each one point increase in the NMSS score lead to a mean increase of 0.027 point in the final SCOPA-PC score. Hence, we performed a secondary analysis using the NMS domains as independent variables and the SCOPA-PC as the dependent variable. Significant domains were 3 and 8 , which were then introduced in the final full model, instead of the total NMSS scores. This final model showed that controlling for other covariates, each point increase in the NMSS domain 3 score would lead to a mean increase of 0.06 point in the SCOPA-PC score $(z=0.03, p<0.001$, $95 \% \mathrm{CI}=0.03,0.08)$. Holding all other covariates constant, a female subject had a mean 1.11 point lower SCOPA-PC score than a male subject $(\mathrm{z}=-1.19, \mathrm{p}=0.234,95 \% \mathrm{CI}=-2.12,-0.11$ ).

Ad-hoc analysis showed similar point estimates, confidence intervals and level of significance.

\section{DISCUSSION}

We found that almost $37 \%$ of our patients were demented as per SCOPA-COG scores and that the most affected domain was memory. The level of education and the UPDRS-Subscale III were the predictors of cognitive impairment. Eighty-five percent of our subjects reported at least one psychiatric symptom and higher scores in domain 3 of NMSS and male gender were predictors of psychiatric complications as assessed per the SCOPA-PC.

Prevalence rates of PDD dementia vary from $25 \%-40 \%{ }^{15,16,17}$. Differences in study design may have affected the outcome measures. Important methodological differences included the tests used to assess cognition, the definition of dementia, the criteria for selecting patients, and whether a cross-sectional or a longitudinal design was used. A recent multicenter Italian study, with 113 patients within a mean age of 68.6 years and a mean education of 8.5 years, using the cut off of 17 for SCOPA-COG reported a relative frequency of PDD of $23.3 \%{ }^{14}$. We found a much higher rate of PDD as per SCOPA scores, but our sample was smaller and the mean age and level of education was lower. Conversely, another study performed in Brazil, with a much lower educational level, presented a prevalence of dementia of $23.8 \%^{2}$. Using logistic regression, they found that age and severity of disease using H\&Y score. However, the point estimates and confidence intervals were not provided.

Another study conducted in a much larger Brazilian sample, also corroborated the effect of age and H\&Y score in predicting dementia ${ }^{18}$. Age was not a predictor in our sample, neither the H\&Y score. However, motor performance as assessed by the UPDRS-Part III was. These seemingly controversial findings are probably attributed to several differences between both studies. Samples sizes are rather different, and while they used a community-based sample, we studied subjects in a tertiary care center. Secondly, our primary analysis used the SCOPA-COG score as a continuous variable in a GLM, while the first study used a logistic regression model with a dichotomous outcome: dementia versus non-dementia. The independent variables included in the model were also different. While the first study took into consideration demographic/motor symptoms (type of treatment, early versus late onset and the symptom symmetry), we used validated clinical scales, controlling for age, gender, disease duration and years of schooling. Indirectly we controlled for psychiatric manifestations of disease, which may influence cognitive performance. The mean age of our sample was also relatively low, and this may have contributed for the lack of effect of age in our study. The first study did not report the age range or the mean of their subjects. Our results are also in agreement with the current literature ${ }^{19,20}$.

Generally, higher age, lower education, disease severity, age-at-onset, higher levodopa dose and use of anticholinergic drugs are considered risk factors for $\mathrm{PDD}^{3,18,21,22}$ and the use of antiparkinsonian drugs is associated with cognitive and psychiatric complications ${ }^{23}$. In our study the total daily dose of antiparkinsonian drugs was not available, however we did not observe an association between the use of dopaminergic drugs, biperiden or amantadine with higher values in the SCOPA-COG and SCOPA-PC. Since in our daily practice we change the treatment when a patient reports cognitive or psychiatric symptoms, we always treat subjects with depression, and the cross-sectional nature of the study, we may have inadvertently introduced confounding.

We found that domain 3 of NMSS, which evaluates mood/apathy, is a predictor of psychiatric complications. However the domain 4, which evaluates perceptual problems/hallucinations was not associated with the final SCOPA-PC score. These findings suggest that the NMSS is a holistic scale to assess the non-motor symptoms of PD. Nevertheless to better evaluate predictors of psychiatric complications we probably need specific scales for each one of those symptoms.

SCOPA-PC score were lower in women than men. Previous studies showed that men have more REM-Sleep Behavior Disorder and Impulse Control Disorders than wom$\mathrm{en}^{24,25}$. Since the SCOPA-PC encompasses both disorders, 
ours findings are in agreement with the current understanding of psychiatric symptoms in PD.

The limitations of our study were the small sample size, the absence of specific scales to evaluate sleep changes, depression, and fatigue which are important symptoms associated with cognitive and psychiatric changes in $\mathrm{PD}^{26}$. Domain 2 and 3 of the NMSS (Sleep/fatigue; Mood/apathy; respectively) did not lead to differences in cognitive performance. While others large studies failed to find that depression is associated with cognitive impairment in $\mathrm{PD}^{27}$, sleep symptoms are commonly associated with cognitive impairment ${ }^{28}$. Second, our study was hospital-based and not community-based, leading possibly to a higher rate of dementia and psychiatric symptoms. However, the objective of this study was to identify the risk factors for dementia and psychiatric complications in our sample, not an overall prevalence. Lastly, we performed a cross-sectional study, and a longitudinal approach would be more accurate. Lastly, the criterion for dementia, based on SCOPA-COG scores, has never been validated in Brazilian subjects. However, the scale has been validated in Portuguese, and we used a cut-off used in similar studies ${ }^{10,14}$. The strengths of this study include the use of validated scales, the global assessment of demographic and clinical aspects, including motor and non-motor symptoms and the use of a multivariate analysis.

In conclusion, our results indicate that cognitive impairment is a common non-motor symptom in PD and the level of education and disease severity are the strongest predictors of PDD. Psychiatric complications were more commonly observed in men, and a clear clinical predictor was not properly established.

\section{AKNOWLEDGMENTS}

We thank the patients for taking part in this study.

\section{References}

1. Shulman LM, Taback RL, Bean J, Weiner WJ. Comorbidity of the nonmotor symptoms of Parkinson's disease. Mov Disord. 2001;16(3):507-10. http://dx.doi.org/10.1002/mds.1099

2. Barbosa MT, Caramelli P, Maia DP, Cunningham MC, Guerra HL, Lima-Costa MF et al.. Parkinsonism and Parkinson's disease in the elderly: a community-based survey in Brazil (the Bambuí study). Mov Disord 2006;21(6):800-8. http://dx.doi.org/10.1002/mds.20806

3. Aarsland D, Andersen K, Larsen JP, Lolk A, Nielsen H, Kragh-Sørensen P. Risk of dementia in Parkinson's disease: A community-based, prospective study. Neurology 2001;56:730-6. http://dx.doi.org/10.1212/WNL.56.6.730

4. Carod-Artal FJ, Vargas AP, Martinez-Martin P, Determinants of quality of life in brazilian patients with Parkinson's disease. Mov Disord. 2007;22(10):1408-15. http://dx.doi.org/10.1002/mds.21408

5. Baldivia B, Brucki SMD, Batistela S, Esper JC, Augusto CD, Rocha MSG. Dementia in Parkinson's disease: a Brazilian sample. Arq Neuropsiquiatr. 2011;69(5):733-8. http://dx.doi.org/10.1590/S0004-282X2011000600002

6. Hughes AJ, Daniel SE, Kilford L, Lees AJ. Accuracy of clinical diagnosis of idiopathic Parkinson's disease:a clinico-pathological study of 100 cases [see comment]. J Neurol Neurosurg Psychiatry. 1992;55(3):181-4. http://dx.doi.org/10.1136/jnnp.55.3.181

7. Movement Disorders Society Task Force on Rating Scales for Parkinson`s Disease. The Unified Parkinson's Disease Rating Scale (UPDRS): status and recommendations. Mov Disord. 2003;18(7):738-50. http://dx.doi.org/10.1002/mds.10473

8. Hoehn MM, Yahr MD. Parkinsonism: onset, progression and mortality. Neurology. 1967;17(5):427-42. http://dx.doi.org/10.1212/WNL.17.5.427

9. Schwab R, England A. Projection technique for evaluating surgery in Parkinson's disease. In: Gillingham FJ, editor. Proceedings of theThird Symposium on Parkinson's Disease; 1969 May 20-22; Edinburgh. Edinburgh: Livingstone; 1969. p. 152-7.

10. Carod-Artal FJ, Martínez-Martin P, Kummer W, Ribeiro LS. Psychometric attributes of the SCOPA-COG Brazilian Version. Mov Disord. 2008;23(1):81-7. http://dx.doi.org/10.1002/mds.21769

11. Verbaan D, Jeukens-Visser M, Van Laar T, rooden SM, Van Zwet EW, Marinus $J$ et al. SCOPA-cognition cutoff value for detection of
Parkinson's disease dementia. Mov Disord. 2011;26(10):1881-6. http://dx.doi.org/10.1002/mds.23750

12. Visser M, Verbaan D, Van Rooden S M, Stiggelbout A M, Marinus $\mathrm{J}$, Van Hilten JJ. Assessment of psychiatric complications in Parkinson's disease: the SCOPA-PC. Mov Disord. 2007;22(15):2221-8. http://dx.doi.org/10.1002/mds.21696

13. Carod-Artal FJ, Martinez-Martin P. Independent validation of the non motor symptoms scale for Parkinson's disease in Brazilian patients. Parkinsonism Relat Disord. 2013;19:115-9. http://dx.doi.org/10.1016/j.parkreldis.2012.08.008

14. Isella V, Mapelli C, Morielli N, Siri C, De Gaspari D, Pezzoli $G$ et al. Diagnosis of possible mild cognitive impairment in Parkinson's disease: validity of the SCOPA-Cog. Parkinsonism Relat Disord. 2013;19(12):1160-3. http://dx.doi.org/10.1016/j.parkreldis.2013.08.008

15. Riedel O, Klotsche J, Spottke A, Deuschl G, Förstl H, Henn F et al. Frequency of dementia, depression, and other neuropsychiatric symptoms in 1,449 outpatients with Parkinson's disease. J Neurol. 2010;257(7):1073-82. http://dx.doi.org/10.1007/s00415-010-5465-z

16. Svenningsson P, Westman E, Ballard C, Aarsland D. Cognitive impairment in patients with Parkinson's disease: diagnosis, biomarkers, and treatment. Lancet Neurol. 2012;11(8):697-707. http://dx.doi.org/10.1016/S1474-4422(12)70152-7

17. Aarsland D, Zaccai J, Brayne C. A systematic review of prevalence studies of dementia in Parkinson's disease. Mov Disord. 2005;20(10):1255-63. http://dx.doi.org/10.1002/mds.20527

18. Munhoz RP, Teive HA, Eleftherohorinou H, Coin LJ, Lees AJ, Silveira-Moriyama L. Demographic and motor features associated with the occurrence of neuropsychiatric and sleep complications of Parkinson's disease. J Neurol Neurosurg Psychiatry. 2013;84(8):883-7. http://dx.doi.org/10.1136/jnnp-2012-304440

19. Pagonabarraga J, Kulisevsky J. Cognitive impairment and dementia in Parkinson's disease. Neurobiol Dis. 2012;46(3):590-6. http://dx.doi.org/10.1016/j.nbd.2012.03.029

20. Riedel O, Klotsche J, Spottke A, Deuschl G, Förstl H, Henn F et al.Cognitive impairment in 873 patients with idiopathic Parkinson's disease: results from the German study on Epidemiology of Parkinson's Disease with Dementia (GEPAD). J Neurol. 2008;255(2):255-64. http://dx.doi.org/10.1007/s00415-008-0720-2 
21. Foltynie T, Brayne CE, Robbins TW, Barker RA. The cognitive ability of an incident cohort of Parkinson's patients in the UK. The CamPalGN study. Brain. 2004;127(Pt 3):550-60. http://dx.doi.org/10.1093/brain/awh067

22. Hughes TA, Ross HF, Musa S, Bhattacherjee S, Nathan RN, Mindham $\mathrm{RH}$ et ao. A 10-year study of the incidence of and factors predicting dementia in Parkinson's disease. Neurology. 2000;54(8):1596-602. http://dx.doi.org/10.1212/WNL.54.8.1596

23. Voon V, Fox SH. Medication-related impulse control disorders and repetitive behaviors in Parkinson disease. Arch Neurol. 2007;64(8):1089-96. http://dx.doi.org/10.1001/archneur.64.8.1089

24. Poletti M, Logi C, Lucetti C, Dell Dotto P, Baldacci F, Vergallo A et al. A single-center, cross-sectional prevalence study of impulse control disorders in Parkinson disease association with dopaminergic drugs. J Clin Psychopharmacl. 2013;33(5):691-4. http://dx.doi.org/10.1097/JCP.0b013e3182979830
25. Szewczyk-Krolikowski K, Tomlinson P, Nithi K, Wade-Martins R, Talbot K, Ben-Shlomo Y et al. The influence of age and gender on motor and non-motor features of early Parkinson's disease: initial findings from the Oxford Parkinson Disease Center (OPDC) discovery cohort. Parkinsonism Relat Disord. 2014;20(1):99-105. http://dx.doi.org/10.1016/j.parkreldis.2013.09.025

26. Riva P,Smith K,Xie SX, Weintraub D. Course of psychiatric symptoms and global cognition in early Parkinson disease. Neurology. 2014;83(12):1096-1103. http://dx.doi.org/10.1212/WNL.0000000000000801

27. Aarsland D, Taylor JP, Weintraub D. Psychiatric issues in cognitive impairment. Mov Disord. 2014;29(5):651-62. http://dx.doi.org/10.1002/mds. 25873

28. Zhu K, Hilten JJ, Marinus J. Predictors of dementia in Parkinson's disease: findings from a 5-year prospective study using the SCOPA-COG. Parkinsonism Relat Disord. 2014;20(9):980-5. http://dx.doi.org/10.1016/j.parkreldis.2014.06.006 